\title{
A. Terrence Conlisk: Essentials of Micro- and Nanofluidics. With Applications to the Biological and Chemical Sciences
}

\author{
Peter Myers
}

Published online: 21 January 2014

(C) Springer-Verlag Berlin Heidelberg 2014

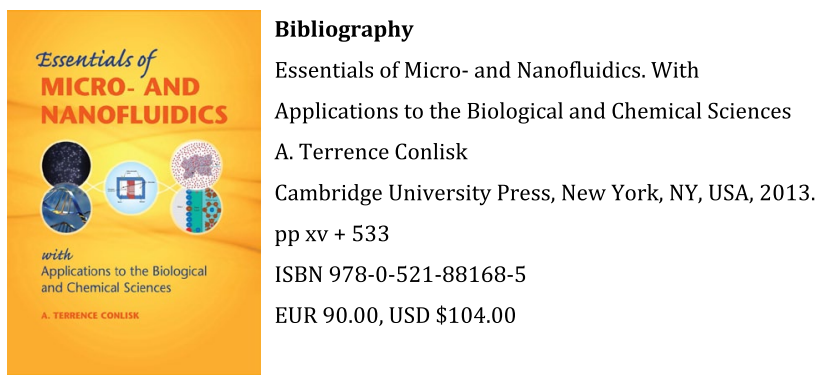

The only thing wrong with this book is its title. Do not believe it, it is not just "The Essentials of Micro and Nano Fluidics" it is far more and much more that the subtitle of "With Applications to the Biological and Chemical Sciences". It is a book that is the essence of modern science that covers aspects of surfaces and their application to the real world. It is a book that covers maths with numerical methods; it is a book that makes you think.

How can a book do so much? Terrence Conlisk has not edited this book, he has done it the hard way and written it himself. This gives the book a common style so that nothing major is repeated from chapter to chapter, as sometimes happens with books put together from different authors. Terrance must also have thought long and hard about the format and in great detail about the eleven individual chapters and then how he could bring all these chapters together into an excellent final chapter on applications. But it does not stop there; in addition to the twelve chapters there are two major appendices and a third on websites. To me this latter is the only weakness as this appendix will be out of date within a year.

As you have realized I was very impressed with this book. It has a refreshing new format and I am sure any forward-looking science lecturer will include it in their lecture course-whether that course is in physics, chemistry or applied maths. Such is the versatility of this book.

For those of you who need more details before you go and spend £72, the twelve chapters cover key principles of viscous flows, electrochemistry, heat and mass transfer phenomena, elements of molecular cell biology and stateof-the-art analytical and computational numerical methods and molecular simulations. In the application chapter examples are presented on the use of the principles described earlier to design rapid molecular analysis devices, biochemical sensing, drug delivery systems, DNA analysis and the design of an artificial kidney. Also included are modern exercise problems using the applications. Yes, as in any first edition, there are mistakes, but these are easily corrected. A book that is well worth the price.

P. Myers $(\bowtie)$

Department of Chemistry, University of Liverpool,

Liverpool L69 3BX, UK

e-mail: Peter.Myers@liverpool.ac.uk 